\section{METHOD OF PRODUCING NITROGEN COMPOUNDS FROM CARBIDS.}

U. S. Patent No. $1,006,927$, to Albert R. Frank, of Halensee, near Berlin. Assignor to Societa Generale Per La Cianamide, of Rome.

This invention is a method of producing nitrogen compounds from carbids, such, for instance, as cyanamids (carbodiimids), cyanids, nitrids, and other like compounds, as applied to the production of which the process would be illustrated by the formula

$$
\text { or } \begin{aligned}
& \mathrm{CaC}_{2}-2 \mathrm{NCaCN}_{2}-\mathrm{C} \text {, } \\
& \mathrm{BaC}_{2}-2 \mathrm{NBaC}_{2} \mathrm{~N}_{2} \text {, }
\end{aligned}
$$

or

$$
3 \mathrm{MgC}_{2}-2 \mathrm{NMg}_{3} \aleph_{2}-60 \text {. }
$$

The process consists in bringing a relatively small part of the carbid mass in a finely divided condition into contact with heated nitrogen to heat said carbid to the reaction temperature, sup-

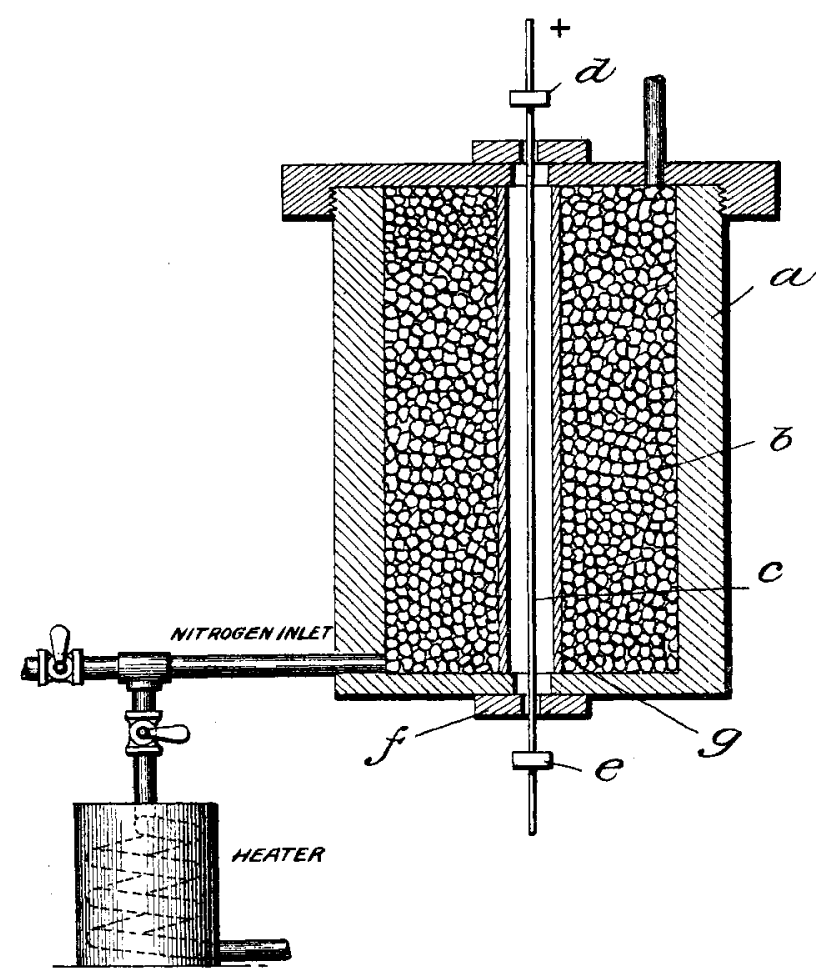

plying nitrogen as the reaction proceeds, thereby maintaining the temperature and continuing the reaction throughout the mass to be converted.

The accompanying illustration shows apparatus in which the process may be carried out.
A SELF-CLEANING STILL.

U. S. Patent No. I,010,508, to W. H. McCune, Vandergrift, Pa.

This invention relates to an apparatus more particularly used for distilling water, with a mechanical arrangement for cleaning at intervals without substantial interruption of the process of distillation or the attention of an operator. It is planned to obviate the usual difficulties of interruption and loss of efficiency in distillation by so designing the apparatus as to clean automatically at regulated intervals.

The accompanying illustration is a sectional elevation, showing the distilling apparatus constructed and arranged in accord-

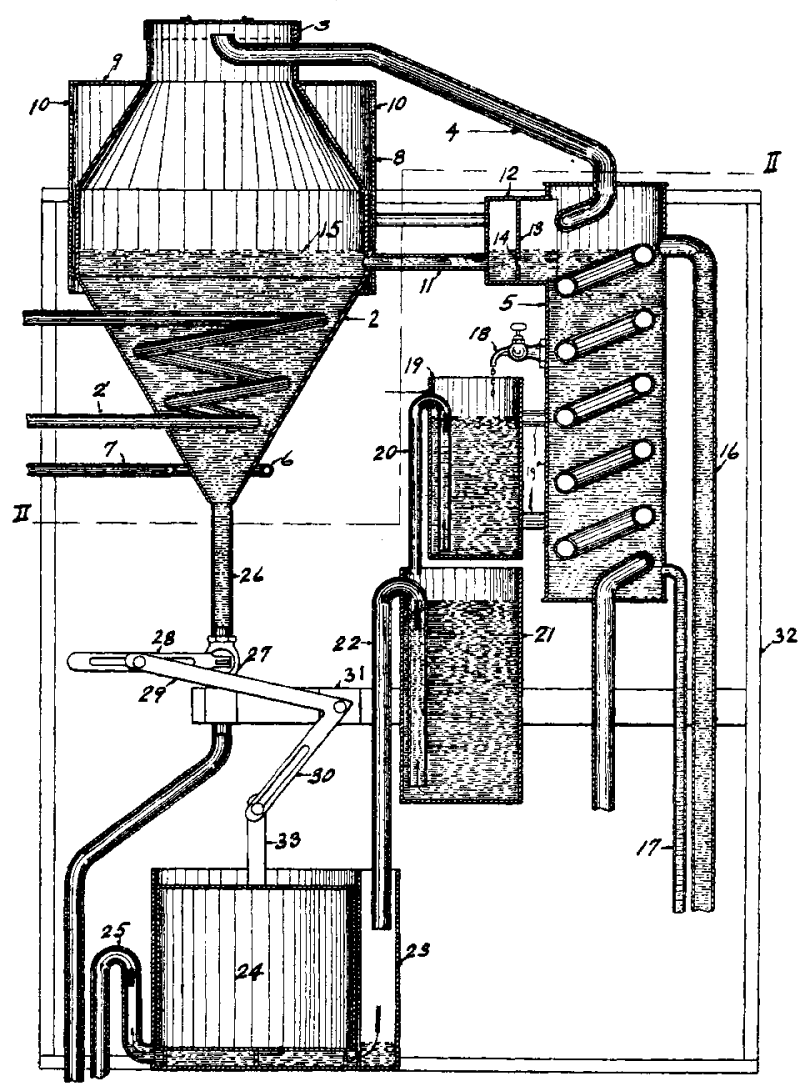

ance with this invention. The new and automatic feature of this device is shown in parts 19,20,21, 22, 23 and 24, and the opening and closing of the flushing valve is accomplished by means of a float. The frequency with which the retort is drained is regulated by the volume of water discharged from the chamber in to the tank I 9 by drip cock I8. 